\title{
Evaluation of blood groups in patients with anti TPO positive
}

\author{
Eşref Araç, İhsan Solmaz \\ Assistant Professor, Deparment of Internal Medicine, University of Health Sciences, Diyarbakır Gazi Yasargil Training \\ and Research Hospital, Diyarbakır, Turkey
}

Background: In studies, ABO blood group system has been shown to be associated with type 2 diabetes mellitus, chronic renal failure, gestational diabetes mellitus, postpartum depression, coronary artery disease, Crohn's disease as well as various cancer types such as stomach, breast, skin cancers and rheumatologic diseases. Aims and Objective: The relationship between anti TPO positivity and ABO blood group system is aimed to be investigated by using blood groups which are the product of genetic structure and easy to identify by considering the relationship between anti TPO positivity and blood group. Materials and Methods: 4312 patients with determined blood groups were included among the patients, who were admitted to the internal medicine outpatient clinics of our hospital between January 2, 2017 and May 28, 2019 and were screeened for thyroid antibodies with thyroiditis susceptibility. Results: The most common blood group was A in both anti TPO positive and anti TPO negative patient groups. The rate of those with $O$ blood group was $2.65 \%$ higher in anti TPO positive group than anti TPO negative group. B blood group was found to be $4.87 \%$ higher in anti TPO negative group than anti TPO positive group (p:0.148). Conclusion: In conclusion, it was found that $O$ blood group may be a risk factor for anti TPO positivity and B blood group is much lower in anti TPO positive ones. However, it is obvious that more comprehensive prospective multicentered clinical and experimental studies are needed to establish the relationship between blood groups and autoimmune diseases, especially autoimmune thyroiditis.

Access this article online

Website:

http://nepjol.info/index.php/AJMS

DOI: 10.3126/ajms.v10i6.25878

E-ISSN: 2091-0576

P-ISSN: 2467-9100

Key words: $\mathrm{ABO}$ and Rh blood groups; Anti TPO; Autoimmune

\section{INTRODUCTION}

Thyroid peroxidase, known as microsomal antigen in 1980s, is the most important and first positive antigen of Hashimoto thyroiditis (HT). ${ }^{1}$ Anti TPO is positive in $90 \%$ of HT patients, regardless of hypothyroidism and euthyroidism. While TPO causes thyroid infiltration and destruction by stimulating immunoglobulin $\mathrm{G}(\mathrm{Ig} G)$ class autoantibodies and TPO specific T cells with high affinity, Anti TPO causes complement-dependent cytotoxicity. ${ }^{2,3}$

The blood groups found on the erythrocyte surface discovered in the $19^{\text {th }}$ century are a kind of cell identity determined by the antigenic structure. The system of blood groups discovered by Landsteiner is the general blood group system known as ABO. In addition, a grouping known as the Rh system and classified as the absence or presence of antigenic structure is used. ${ }^{4}$

In terms of genetics, blood groups are a qualitative feature whose phenotypic variation is completely reflecting the genetic structure in which the environmental effect is zero. In this sense, blood groups are very important in terms of reflecting the genetic structure. Blood group antigens are genetically coded and these antigens can be susceptibility factors to some diseases and resistance factors for others. In studies, ABO blood group system has been shown to be associated with type 2 diabetes mellitus, chronic renal failure, gestational diabetes mellitus, postpartum depression, coronary artery disease, alopesia areata, gastroduodenal ulcers, Crohn's disease, hepatitis B infection, as well as various cancer types such as

\section{Address for Correspondence:}

Dr. Eşref Araç, Assistant Professor, Deparment of Internal Medicine, University of Health Sciences, Diyarbakır Gazi Yasargil Training and

Research Hospital, Elazığ Road, Kayapınar, Diyarbakır, Turkey. -21070. Tel No: 00905335124421. E-mail: esref.arac@sbu.edu.tr (C) Copyright AJMS 
stomach, brain, breast, skin cancers and rheumatologic diseases. ${ }^{5-17}$ Although there are recent studies examining the relationship between thyroid diseases and blood group, ${ }^{18,19}$ there are no studies examining the relationship between anti TPO positivity and blood groups. The relationship between anti TPO positivity and ABO blood group system is aimed to be investigated by using blood groups which are the product of genetic structure and easy to identify by considering the relationship between anti TPO positivity and blood group.

\section{MATERIALS AND METHODS}

This study was designed retrospectively and the data were obtained through the hospital information management system (HIMS). After obtaining the ethics committee approval by the clinical observation ethics committee of our hospital on June 28, 2019, 4312 patients with determined blood groups were included among the patients, who were admitted to the internal medicine outpatient clinics of our hospital between January 2, 2017 and May 28, 2019 and were screeened for thyroid antibodies with thyroiditis susceptibility. Anti TPO was measured with electrochemiluminescence method on Cobas E601 device (Roche Diagnostic, Germany). The reference range for anti TPO was accepted $<34 \mathrm{IU} / \mathrm{ml}$. The blood group distributions of 628 anti TPO positive and 3684 anti TPO negative patients were analyzed.

\section{Statistical analysis}

Statistical evaluation was performed using SPSS 20 for Windows (IBM SPSS Inc., Armonk, NY, USA). Normal distribution of data has been evaluated with KolmogorovSmirnov test. Normal distribution of numerical variables was shown as mean \pm standard deviation. Chi-square and Fisher's exact tests were used to compare categorical data. $\mathrm{p}<0.05$ was considered statistically significant.

\section{RESULTS}

Eighty five percent (n: 3665) of the patients included in our study were female and $15 \%$ (n: 647) were male. Of the 628 patients who were anti TPO positive, 561 (89\%) were female and $67(11 \%)$ were male. Blood group distribution of anti TPO positive patients was determined as; $35.35 \%$ A Rh (+), 32.80\% O Rh (+), $12.89 \%$ B Rh (+), 5.78\% AB $\mathrm{Rh}(+), 4.61 \% \mathrm{~A} \mathrm{Rh}(-), 4.23 \%$ ORh (-), 2.87\% B Rh (-) and $1.11 \% \mathrm{AB} R \mathrm{Rh}(-)$. Among anti-TPO positive patients, $86.82 \%$ Rh positivity and $13.18 \%$ Rh negativity were detected.

Blood group distribution of anti TPO negative patients was determined as; 34.01\% A Rh (+), 30.86\% O Rh (+), $18.13 \% \mathrm{~B} R \mathrm{Rh}(+), 5.99 \% \mathrm{AB} \mathrm{Rh}(+), 4.12 \% \mathrm{~A} \mathrm{Rh}(-)$,
$3.52 \% \mathrm{O}$ Rh (-), 2.60\% B Rh (-) and 0.67\% AB Rh (-). Among anti-TPO negative patients, $88.99 \%$ Rh positivity and $11.01 \%$ Rh negativity were detected.

The blood group distribution of the anti-TPO positive and negative patients is given in Chart 1 .

In our study, 39,96\% A, 37,03\% O, 15,76\% B, 6,89\% AB blood groups were detected in anti TPO positive patients. 40.81\% A, 34.38\% O, $18.53 \%$ B, $6.66 \%$ AB blood group were detected in anti TPO negative patients. (Chart 2).

The most common blood group was A in both anti TPO positive and anti TPO negative patient groups. The rate of those with O blood group was $2.65 \%$ higher in anti TPO positive group than anti TPO negative group. B blood group was found to be $4.87 \%$ higher in anti TPO negative group than anti TPO positive group (p: 0.148). When the patients were classified according to blood groups, gender and age did not differ in terms of blood groups ( $p>0.05)$.

\section{DISCUSSION}

In our study, we found that the ratio of $\mathrm{O}$ blood group was higher in anti TPO positive patients than in anti TPO



Chart 1: The blood group distribution of the anti-TPO positive and negative patients



Chart 2: Distribution of blood groups according to anti TPO without Rh factor 
negative patients. In addition, the proportion of B blood group was significantly lower in patients who were antiTPO positive. The incidence of Rh antigen was found to be similar in both patient groups. Recently, the number of studies investigating the relationship between blood groups and autoimmune and rheumatologic diseases, in addition to malignancies, is increasing. Studies have shown that many autoimmune diseases such as multiple sclerosis, celiac disease, rheumatoid arthritis and alopecia areata may be associated with blood groups. ${ }^{13,20}$ The pathogenesis of this relationship has not yet been established. A study conducted in Ankara in 2019 showed that there may be a relationship between O blood group and Hashimoto's thyroiditis and that the risk of autoimmune thyroid disease may be lower in patients with $\mathrm{AB}$ blood group..$^{18}$ Some previous studies have shown that the rate of $\mathrm{O}$ blood group is higher in some autoimmune diseases such as familial Mediterranean fever, systemic lupus erythematosus, and systemic sclerosis. ${ }^{7}$ Since people with O blood group do not have $\mathrm{A}$ and $\mathrm{B}$ antigens, there are anti-A and anti-B antibodies that develop against them. The high rate of autoimmune thyroid diseases in the blood group $\mathrm{O}$, in which antibodies against both blood group antigens are present, has emerged that there may be a relationship between blood group antibodies and these diseases, but there is no clear evidence to reveal this relationship yet.

Our study had some limitations. These can be counted as retrospective file scanning, including only follow-up patients in a single center, and absence of a control group. Therefore, it is certain that the data obtained will not reflect the general population. Findings supporting our hypothesis were obtained, but our study does not reflect nationwide data.

\section{CONCLUSION}

In conclusion, it was found that $\mathrm{O}$ blood group may be a risk factor for anti TPO positivity and B blood group is much lower in anti TPO positive ones. However, it is obvious that more comprehensive prospective multicentered clinical and experimental studies are needed to establish the relationship between blood groups and autoimmune diseases, especially autoimmune thyroiditis.

\section{REFERENCES}

1. Brix TH, Kyvik KO and Hegedüs L. A Population-Based Study of Chronic Autoimmune Hypothyroidism in Danish Twins. J Clin Endocrinol Metab 2000;85(2):536-539.

2. McLachlan SM and Rapoport B. Thyroid Peroxidase as an Autoantigen. Thyroid. 2007;17(10):939-948.

3. Khoury EL, Hammond L, Bottazzo GF and Doniach D. Presence of the organ-specific "microsomal" autoantigen on the surface of human thyroid cells in culture: its involvement in complementmediated cytotoxicity. Clin Exp Immunol 1981;45(2):316-328.

4. Şaylı BS. Temel Medikal Genetik Ankara: Ankara Üniversitesi Tıp Fakültesi Yayınları; 1982. 430 p.

5. Teshome Y, Mekonen W, Birhanu Y and Sisay T. The association between $A B O$ blood group distribution and peptic ulcer disease: a cross-sectional study from Ethiopia. J Blood Med 2019;10:193-197.

6. Ben Q, Liu J, Wang W, Guo F, Yao W, Zhong J, et al. Association between $\mathrm{ABO}$ blood types and sporadic pancreatic neuroendocrine tumors in the Chinese Han population. Oncotarget 2017;8(33):54799-54808.

7. Çildağ $S, K a r a Y$ and Şentürk T. ABO blood groups and rheumatic diseases. Eur J Rheumatol 2017;4(4):250-253.

8. Allouh MZ, Al Barbarawi MM, Hiasat MY, Al-Qaralleh MA and Ababneh El. Glioblastoma and $\mathrm{ABO}$ blood groups: further evidence of an association between the distribution of blood group antigens and brain tumours. Blood Transfus 2017;15(6):543-547.

9. Ye BD, Kim BM, Jung $S$, Lee $H$, Hong $M$, Kim $K$, et al. Association of FUT2 and $A B O$ with Crohn 's disease in Koreans. J Gastroenterol Hepatol [Internet]. 2019 Aug 7 [cited 2019 Aug 14];jgh.14766. Available from: http://www.ncbi.nlm. nih.gov/pubmed/31260595.

10. Liu J, Zhang S, Liu M, Wang Q, Shen $\mathrm{H}$ and Zhang Y. Distribution of $A B O / R h$ blood groups and their association with hepatitis $B$ virus infection in 3.8 million Chinese adults: A population-based cross-sectional study. J Viral Hepat 2018;25(4):401-411.

11. Song C, Leng J, Wang L, Li W, Zhang S, Wang W, et al. ABO blood types and postpartum depression among Chinese women: A prospective cohort study in Tianjin, China. Women Health 2018;58(6):685-698.

12. Timur AA, Barnard J, Murugesan G, Gandhi S, Bhatt DL and Kottke-Marchant $\mathrm{K}$. The relation between $\mathrm{ABO}$ blood types and clinical and platelet function parameters in patients who underwent percutaneous coronary intervention. Coron Artery Dis 2019;30(1):51-58.

13. İslamoğlu ZGK and Unal M. Is there an association of $A B O$ blood groups and Rhesus factor with alopecia areata? J Cosmet Dermatol 2018;17(6):1271-1274.

14. Li N, Xu M, Li C-F, Ou W, Wang B-X, Zhang S-L, et al. Prognostic role of the $A B O$ blood types in Chinese patients with curatively resected non-small cell lung cancer: a retrospective analysis of 1601 cases at a single cancer center. Chin J Cancer 2015;34(3):54.

15. Yu H, Xu N, Li Z-K, Xia H, Ren H-T, Li N, et al. Association of ABO Blood Groups and Risk of Gastric Cancer. Scand J Surg [Internet]. 2019 Jul 7 [cited 2019 Aug 14];145749691986388. Available from: http://www.ncbi.nlm.nih.gov/pubmed/31282314

16. Sapanont K, Sunsaneevithayakul $P$ and Boriboonhirunsarn D. Relationship between $\mathrm{ABO}$ blood group and gestational diabetes mellitus. J Matern Neonatal Med 2019;1-5.

17. Celić D, Lipozenčić J, Kolarić B, Ferenčak G, Rajković JK and Borlinić T. Association between Blood Group and Nonmelanoma Skin Cancers (Basal Cell Carcinoma and Squamous Cell Carcinoma). Int J Environ Res Public Health 2019;16(13):2267.

18. Dağdeviren $M$, Ateş I, Demir BF, Ergün E, Yıldız $C$ and Altay M. Investigation of blood groups in benign thyroid diseases in Turkey. Endocr J [Internet]. 2019 Jul 12 [cited 2019 Aug 14]; Available from: http://www.ncbi.nlm.nih.gov/pubmed/31308303

19. Turcios S, Lence-Anta JJ, Santana J-L, Pereda CM, Velasco M, Chappe M, et al. Thyroid volume and its relation to anthropometric measures in a healthy cuban population. Eur Thyroid J 201;4(1):55-61.

20. Valikhani M, Kavand S, Toosi S, Kavand G and Ghiasi M. ABO blood groups, rhesus factor and pemphigus. Indian J Dermatol 2007;52(4):176-178. 
Authors Contribution:

Contribution of all Authors towards this manuscript:

EA-Concept and design of the study, manuscript preparation, statistically analyzed and interpreted, critical revision of the manuscript, review of the study;

is- Reviewed the literature, collected data, statistically analyzed and interpreted, helped in preparing first draft of manuscript, review of the study.

Orcid ID:

Dr. Eşref Araç - (i) http://orcid.org/0000-0001-6041-3817

Dr. İhsan Solmaz - (i) http://orcid.org/0000-0002-6624-8063

Source of Support: We received no financial support for the research, authorship, and/or publication of this article. Conflict of Interest: None declared. 